\title{
Prevention of Cervix Cancer in a Low Resources Country: Operational and Clinical Aspects of a Screening's Network in a Suburb of Abidjan (Côte d'Ivoire)
}

\author{
Horo Apollinaire, Koffi Abdoul*, Aka Kacou Edele, Seni Konan, Koné Mamourou \\ University Hospital Yopougon, Abidjan, Côte d'Ivoire \\ Email: horoapollinaire@yahoo.fr, "kkoffiabdoul@yahoo.fr, senikonan@yahoo.fr, edelpap@gmail.com, \\ mamourouk@hotmail.com
}

Received 16 November 2015; accepted 25 January 2016; published 29 January 2016

Copyright (C) 2016 by authors and Scientific Research Publishing Inc.

This work is licensed under the Creative Commons Attribution International License (CC BY).

http://creativecommons.org/licenses/by/4.0/

c) (i) Open Access

\begin{abstract}
Background: Cancer of the cervix is the most common cancer and the leading cause of death by cancer in women in developing countries. According to WHO, there were in 2002 in the world more than 500,000 new cases of cervical cancer, with more than $90 \%$ in developing countries. Secondary prevention of cervical cancer is done through screening of precancerous lesions and early diagnosis of cancer followed by treatment. Objectives: Our experience was reported in the management of a network of screening in the prevention of cancer of the uterine cervix. Method: After a program of training and upgrade to a pool of specialist doctor of obstetrics and gynaecology and midwifery centers health on visual screening methods, a reference site that is also a trainer site was defined and equipped with video-colposcopy and cryotherapy device. In April 2014, four peripheral sites have been installed with an equipment of lamp, magnifying glasses, acid acetic $5 \%$ and Lugol's iodine. The screening network has been implemented and works on the model of reference-cross-reference. Results: The assessment of a year's activity of the peripheral centers reported 993 patients, 653 consultations at the reference site, 106 precancerous lesions $(6 \%)$, and 86 cases of references. The age of attendance peak lies in the age group of 35 - 55 years. Conclusion: The improvement of women's participation requires organized screening, mass communication strategies, and systematic proposal of screening in consultation.
\end{abstract}

\section{Keywords}

Network, Screening, Cervical Cancer

\footnotetext{
${ }^{*}$ Corresponding author.
}

How to cite this paper: Apollinaire, H., Abdoul, K., Edele, A.K., Konan, S. and Mamourou, K. (2016) Prevention of Cervix Cancer in a Low Resources Country: Operational and Clinical Aspects of a Screening's Network in a Suburb of Abidjan (Côte d'Ivoire). Open Journal of Obstetrics and Gynecology, 6, 85-91. http://dx.doi.org/10.4236/ojog.2016.61010 


\section{Introduction}

Cancer of the cervix is the most common cancer and the leading cause of death by cancer in women in developing countries. According to WHO, there were in 2002 in the world more than 500,000 new cases of cervical cancer, with more than $90 \%$ in developing countries. In sub-Saharan Africa, 72,000 new cases were recorded in the same year and 56,000 women died as a result of cancer of the cervix [1]. Primary prevention of cervical cancer is essentially based on healthy lifestyles and HPV vaccination.

Secondary prevention of cervical cancer is done through screening of precancerous lesions and early diagnosis of cancer followed by adequate treatment. The main techniques used are: cytology of the cervix cells and screening by visual inspection of the cervix. In limited resource countries, cytology is inaccessible due to the insufficient number of laboratory, and its high cost [2]. Demonstration projects, initiated in six countries in the African Region and coordinated by WHO showed efficacy, the safety and the performance of the method of screening by visual inspection [1] [3].

The cervical cancer is preventable and curable if it is detected early and treated properly. In sub-Saharan Africa, the lack of policy, effective strategies and program screening and treatment largely explains the high prevalence rates and mortality due to cancer of the cervix in countries [1]. Indeed, without access to prevention and quality screening services, the majority of women consult when the cancer is at an advanced stage.

Cancer is responsible for a heavy economics and psychology. According to a 1993 World Bank analysis, a cost of cancer screening cervical practiced every five years amounted to US \$100 per year of life adjusted for disability (Daly) won, compared to US \$2600 per Daly for the treatment of invasive cancers and palliative care [1]. In almost all countries in the African Region, populations and care providers lack information on the methods of prevention and support for cancer of the cervix [2]. In some communities, the ignorance and the lack of information about the disease are also barriers to prevention [3] [4].

Cervical cancer prevention strategies require the synergy of action of several entities. It is actions of the authority's political and administrative organization of the health system, the availability of resources for screening activities, and the action of health personal. We decided to share our experience with the animation of a network of screening in cervical cancer prevention. More specifically, the objectives are to present the organization's network, report the preliminary results and analyze the difficulties.

\section{Materials and Method}

\subsection{Base of Network Creation}

Implementation network we went on the definition of a reference site that is also a trainer site. And so from the first quarter of 2012, several actions have been initiated: upgrading doctor's gynecologists on the various methods of screening but with emphasis on Visual inspection and by the Organization of postgraduate teaching colposcopy.

In March 2012, twenty doctors underwent a theoretical and practical training on such terms. This training supervised by the university hospital of Yopougon Abidjan, the Society of Gynecology and Obstetrics of Côte d'Ivoire (SOGOCI), UNFPA, the national program of fight against cancer (PNLCa) was created by four graduate teachers for colposcopy of the unit training and research of medical sciences of the University Felix Houphouet-Boigny, Abidjan.

Midwives through their private organization, Association of Ivorian midwives (ASFI), Union of Ivorian midwives (SYNSFI) have been incorporated into the initiative. A pool 75 midwives of 20 hospitals of first contact of the neighbourhoods and suburbs of Abidjan was trained in methods of screening for Visual inspection. Latter should be able to do the counseling of women and to carry out Visual inspection.

\subsection{Framework}

Service of Gynecology of Yopougon hospital is therefore the reference site. It is located to the West of Abidjan and covers a radius of health about 100 kilometers from Abidjan and suburban covering 8 facilities of level 1, a general in built-up areas hospital and 4 general hospitals in the suburbs. It hosts an office of a computer equipped with a video-colposcopy, device for cryotherapy. Four sites peripheral drivers first opened in April 2014 and then followed other 16. They are animated by midwives.

Apart from the material the network made a flat kit (1.55 euro) screening with especially a book, gloves, a 
speculum. This book contains a schedule of follow-up of screening, a diagram of the cervix on which it represents eventually abnormality on the basis of clinical examination. The benefit of selling the kits serves to renew the equipment (speculum, cotton, acetic acid, Lugol iodine...).

The office equipment has been done by the French NGO donations (Foundation GYN' AIDE and SIBYLLA HESSE) in the prevention of cancer of the cervix. The network received further test kits of the same NGO in April 2014 with a value of EUR 4500. This allowed the installation at the second time of other screening units and the start of activities in some health facilities of first contact. Screening for cervical cancer is now a part of the minimum package of activity such health centers. There receive quarterly supervision by two gynaecologists of the reference site.

\subsection{Method of Work}

It is based on the organizational structure of the health system of Cote d'Ivoire with reference and cross-reference modes. It's a pyramid scheme. There are basic institutions, first contact; clinic, center of urban health, community-based health training. Care providers consist of generalist physicians, nurses, midwives, caregivers help. It offers basic health care. At the secondary level, these are general hospitals, hospital regional centers equipped with block procedures, the services of medical and surgical specialties. At the Summit, at the tertiary level, these are the university hospitals center (UHC) and Institutes of health. Outside the healthcare of all specialties, is the training of the country's health.

The reference site is a hospital level 3, University hospital of yopougon (Abidjan). Peripheral sites are the establishment of first contact, level 1 (Edmond Basque Hospital of Plateau [EBHP], health's center Marie Thérèse Houphouet Boigny [MTHBHA] Adjamé, Communautary health’ center of Cocody [CHCC]), and level 2 (General hospital of Anyaman [GHA]).

\subsection{Circuit of Patients}

Gynecology's service at the Yopougon University Hospital (UHY) is the main center by all suspected cases pending implementation based on other colposcopy. There are 20 peripheral sites, four functional daily. The other 16 have a few activities since three months.

\subsection{Peripheral Center}

Daily two midwives are assigned to screening activities. Every morning in consultation waiting room, the midwife carries out counseling on screening to patients (from 25 to 65) whatever their reason for consultation. It provides precise information on the prevention of cervical cancer. She listens, answers questions, and allows the woman to make her own decision. In addition, the midwife or the doctor systematically offers screening in consultation. Then, the cervical examination is conducted by the application of acetic acid (VIA) and Lugol's iodine (VILI). Visual methods (VIA and VILI) involved examination of the cervix with the naked eye (without magnification) using a focus lamp or a torch light. In the most recent studies, VIA and VILI were categorized as positive or negative according to the criteria of the International Agency for Research on Cancer (IARC) [5].

After a first normal examination, a control is done a year later and then every three years until 65. Data are recorded in the book of screening of the patient and in a register relating to the hospital. When abnormalities, there are two possibilities: the image is photographed and transmitted by smart phone to a doctor's reference site that gives its opinion. A scheme is represented in the book, a consultation ballot is delivered to the patient, and she consults at the reference site. When patients are eligible for cryotherapy they are immediately referred (Figure 1).

\subsection{Reference Site}

It receives all patients referred. A secretariat is assigned to the management of appointments by telephone in coordination with other sites. It ensures the permanent programming of medical specialists. Counseling to any patient in consultation is carried out either by the midwife in the hall waiting or by doctor's gynecologists in the course of its examination. A gynecologist and a doctor in training of specialty of obstetrics and gynaecology performs screening every day (10 doctors per week). A colposcopy, if necessary a biopsy for histological examination is carried out. Cryotherapy or surgery is performed when an indication requires it. Photo No. 2 
presents the screening network mapping. Colposcopy results are categorized according to the criteria of the International Agency for Research on Cancer [6] (Figure 2).

\section{Results}

Estimated currently to 105 the number of practitioners animating the screening network. The summary balance sheet after a year's activities of four peripheral centers is reported in Table 1, Table 2. It evaluates to 993 patients whose 59 precancerous lesions (6\%). There were 653 consultations, whose 86 cases of references to reference site. Table 3 presents the observed lesions and the therapeutic attitude.

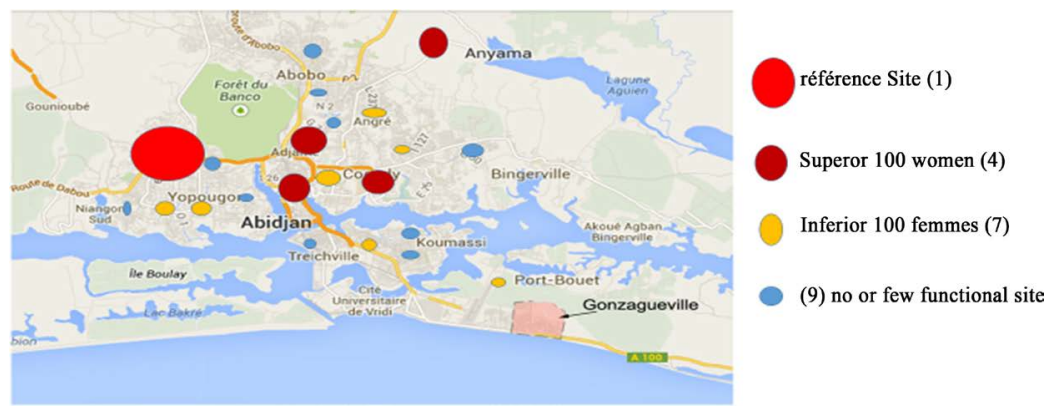

Figure 1. Screening network "map”.

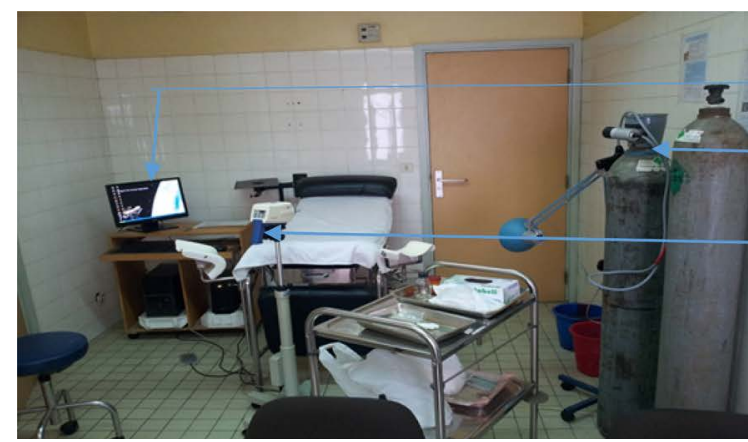

Computer: bank photography

Co2 bottle + Cryotherapy's

device

Figure 2. Screening room with equipment.

Table 1. Population by age group and site.

\begin{tabular}{cccccc}
\hline AGE & EB HP & HGA & MTHBH A & CHCC & UH YOPOUGON \\
\hline $\mathbf{1 5}-\mathbf{2 4}$ & 42 & 34 & 9 & 2 & 22 \\
$\mathbf{2 5}-\mathbf{3 4}$ & 92 & 41 & 18 & 29 & 129 \\
$\mathbf{3 5}-\mathbf{4 4}$ & 171 & 124 & 87 & 48 & 287 \\
$\mathbf{4 5}-\mathbf{5 4}$ & 36 & 83 & 58 & 23 & 159 \\
$\mathbf{5 5}-\mathbf{6 5}$ & 25 & 38 & 27 & 6 & 56 \\
\hline
\end{tabular}

Table 2. Number and results of the visual inspection.

\begin{tabular}{|c|c|c|c|c|c|}
\hline & \multicolumn{2}{|c|}{ VIA } & \multicolumn{2}{|c|}{ VILI } & \multirow{2}{*}{ TOTAL } \\
\hline & Négative & Positive & Négative & Positive & \\
\hline Edmond Basque Hospital Plateau (EBHP) & 352 & 14 & 352 & 14 & 366 \\
\hline Anyama General Hospita (GHA) & 300 & 20 & 299 & 21 & 320 \\
\hline $\begin{array}{c}\text { Marie Thérèse Houphouët Boigny Hospital, } 220 \text { Logements } \\
\text { ADJAME (MTHBHA) }\end{array}$ & 184 & 15 & 182 & 17 & 199 \\
\hline Community Health Center Cocody (CHCC) & 102 & 6 & 101 & 7 & 108 \\
\hline $\begin{array}{c}\text { Total/ } \\
\text { Pourcent (PCL) }\end{array}$ & 938 & $\begin{array}{c}55 / \\
5.53 \%\end{array}$ & 934 & $\begin{array}{c}59 / \\
5.93 \%\end{array}$ & 993 \\
\hline
\end{tabular}


Table 3. Colposcopic exam' result and therapy.

\begin{tabular}{ccc}
\hline Lesions & Number (\%) & Treatment \\
\hline Cervicitis/Ectropion & $14(12.8)$ & Control at 1 year \\
\hline & & Medical supervision 31 \\
Atypical transformation grade I & $66(60.5)$ & $\begin{array}{c}\text { Cryothérapy } 14 \\
\text { Electroconization } 03\end{array}$ \\
\hline Atypical transformation grade II & & Biopsy 18 \\
\hline Cancer & $26(23.8)$ & Biopsy 23 \\
\hline Total & $3(2.7)$ & Electroconization 03 \\
\hline
\end{tabular}

11 patients with grade I lesion biopsies have been benefited a cryotherapy and are under surveillance. For grades II, 6 new recommendations made, 15 surveillance underway, 3 lost from view. Squamous Cell Carcinoma of the cervix have been confirmed out of surgical treatment, so under chemotherapy.

\section{Discussion}

The prevention of the uterine cervix's cancer requires the synergy of several entities [3] [4]. In developing countries the resources are limited and priority-oriented that preventive curative actions [7]. In Côte d'Ivoire the national program of fight against cancer (PNLCa) is of recent creation. The national standards and guidelines for the prevention of cancer of the cervix have been developed in August 2013 and published in the first quarter 2015. They provide visual inspection with acetic acid (VIA) screening every three years.

The screening was reserved for a social category to pay for cytology. Therefore, the cervical smear is not routinely recommended in routine consultation.

Pending a national strategy, seemed timely to organize ourselves in network modeled under so a reference model and against reference for the purpose to educate the medical caregivers by their training, their effective integration in screening activities and serve then relay in communities. Now screening is part of the minimum package of first contact service activity.

\subsection{Organizational Modalities of Screening}

Is defined usually two ways to deliver screening services: within an organized program or opportunistically [4]. As part of an organized program, all the elements of the screening process are integrated, including recruitment and retention strategies to maximize participation, guidelines for screening and monitoring, as well as information and systems for monitoring quality assurance and evaluation of the program, so as to optimize the operation and quality of screening [4] [7] [8].

Screening can also be offered to "opportunistic" way people, that a screening test is available to persons who consult a health professional. Support is then left to the discretion of the consulted professional. For the moment we are opportunistic and individual screening. However if it is possible to achieve high coverage with the opportunistic approach, he was criticized especially its low efficiency, because the overscreening of women who are at risk, common with this type of approach [9] [10].

In addition access to the center remains difficult for some populations. Primary prevention is not available. Vaccines are sold in private pharmacy. The cost is still high (about 30 euros the dose). Our approach also exposes the risk of detection missed error, wrong diagnosis. However the colposcopy image data bank, overseeing the peripheral centers are ways to minimize these risks. Our centers are not equipped in device for cryotherapy, which also increases the risk of loss but approach opportunistic we are allows to retain women and significantly reduce this risk.

The disparity in participation is linked to the accessibility of the center, the population density and also at the level of education of visitors to the center. Downtown Edmond Basque is located in the Plateau business center of the economic capital, Abidjan. The general hospital of Anyama is a suburb with a high density. The analysis 
of the results shows that the basis of screening remains information. When the woman is informed, she submits to testing. There is no or almost no systematic consultation of screening for women due to the lack of information on the existence of the site of screening and cancer of the cervix. The attendance peak is located in the March 8 period devoted to the world women's day period during which awareness messages are highlighted.

A summative study in the UHC of Fianarantsoa in Madagascar shows that the rate of screening by VIA is $0.47 \%$ despite the existence of means of screening. It concludes that efforts are yet to be deployed to strengthen the participation of women in the screening [11]. Actions to promote accession to the screening have been identified on the basis of data from the literature two meta-analyses published by the Cochrane Collaboration in 2002 and 2006 showed that: education activities with a video or slideshow support multiplied by 4.6 the rate of adherence to screening for cervical cancer. The review of screening by a woman doctor multiplied by 2.5 the rate of adherence to screening for cancer of the cervix [12].

Membership of screening varies with age. There is a peak between 35 and 45 years old. In France, it also takes account of the social security scheme of women [11]. Screening coverage is 60\% among 25 - 34 year-olds, $67 \%$ of women aged 35 - 44 and $60 \%$ in the 45 - 54 age group. This rate falls below $50 \%$ after 55 years. The coverage rate was lowest for women affiliated to the social system independent (RSI; 54\%) and those affiliated with social mutuality agricultural (MSA; 51\%) over the period 2007-2009 [10] [13].

The strength of the network today remains: professionals are appropriate and lead awareness for screening activities, other sites have been opened and function normally.

Weaknesses remain the management of patients with precancerous lesions and which are lost from view, supported by the patients itself without insurance cases of cancer and views electroconisation they are from disadvantaged social status, the means necessary for the accession of screening women.

\subsection{How Improve the Screening}

The sustainability of our network is currently based on the efficient use of the benefits of screening kits for sale, donations to NGOs. All work carried out to date advocate screening organized as some European countries and Australia [9] [10] [14].

It further recommends:

- Implementation of a system of specific for screening information and follow-up of women the reduction of barriers to the accessibility to the increase of the sites and the provincial network organization is an axis [1] [2] [4].

- Continuing education of professionals allows to integrate a large number of professionals in the screening network. Asonganyi E, et al. [15], Zahedi L [16] in their studies suggest provider non-compliance factors include lack of awareness and knowledge about protocols, time and cost constraints, and lack of infrastructure or training on performing. These results suggest that prevention initiatives should be multifaceted including education, resource needs assessments and improvement, training as well as strategies on costing and practitioner time studies.

- In the opportunistic approach, the custom invitation of women by their physicians or by one other body (Organization, health mutual, district, and village) could more incentive [1] [9] [12] [14].

- Mass communication strategies: the use of mass media, such as television, radio or newspapers to promote screening is a relatively expensive strategy, whose effectiveness cannot be guaranteed if the measure is not accompanied an increase of the offer by clinicians or a reduction of barriers to access services [1] [2] [5].

- The achievement of annual campaign of screening involving local authorities, community leaders.

\section{Conclusion}

The active participation of health personnel in the prevention of cancer of the cervix by the animation of a network allows informing and training personal. These health workers will form relays in the community. The improvement of women's participation requires organized screening, mass communication strategies, and the systematic proposal of screening in consultation.

\section{Competing Interests}

The authors have declared that no competing interests exist. 


\section{References}

[1] WHO (2008) Prevention and Fight against Cancer: A Strategy for the African Region of Who. World Health Organization, Regional Office for Africa (WHO/AFR/RC58/4). www.Afro.who.int

[2] UNFPA (2011) Comprehensive Cervical Cancer Prevention and Control Programme Guidance for Countries.

[3] Regional Office for Africa AFR/RC60/60 (2010) Cancer of the Cervix in the WHO African Region: Current Situation and Prospects. www.Afro.who.int

[4] The national Institute of Public Health of Quebec (2009) An Optimization of Screening Cervix Cancer in Quebec. Direction of Biological, Environmental and Occupational Risks. http://www.inspq.qc.ca

[5] Sankaranarayanan, R. and Wesley, R. (2003) A Pratical Manual on Visual Screening for Cervical Neoplasia. IARC Press, Lyon, IARC Technical Publication No. 41.

[6] Sellors, I. and Sankaranarayanan, R. (2003) Colposcopy and Treatment of Cervical Intraepithelial Neoplasia: A Beginner's Manual. IARC Press, Lyon.

[7] Sankaranarayanan, R., Budukh, A.M. and Rajkumar, R. (2001) Efficient Programme of Cervix Cancer Screening in Low Ressources Countries. Bulletin of the World Health Organisation, 79, 954-962.

[8] Chignier, P. (2014) Relevance of Screening Cervix Cancer within a Health Care Facility. Gynaecology and Obstetrics. http://dumas.ccsd.cnrs.fr/dumas-01079707

[9] Fahs, M.C., Plichta, S.B. and Mandelblatt, J.S. (1996) Cost-Effective Policies for Cervical Cancer Screening. An International Review. Pharmacoeconomics, 9, 211-230. http://dx.doi.org/10.2165/00019053-199609030-00004

[10] Smith, R.A. (2006) Cancer Screening in the USA. Journal of Medical Screening, 13, 4853.

[11] Andrianampy, H.A., Raktomahenina, H. and Rakotondraisa, J.M. (2004) Cervix’ Cancer: Evaluation after Launch of a Screening Programm. Journal Africain du Cancer, 6, 85-90. http://dx.doi.org/10.1007/s12558-014-0312-7

[12] High Authority of Health (HAS) (2013) Screening and Prevention of Cancer of the Cervix. Update of the Repository of the Periodic Health Examination (EPS) Practices. Report of the High Authority of Health (HAS).

[13] Duport, N., Haguenoer, K., Ancelle-Park, R. and Bloch, J. (2007) Organized Screening for Cervix Cancert; Epidemiological Evaluation of the Four Departments “Drivers” Chronic Diseases and Injuries. www.invs.sante.fr

[14] Horo, A., Jaquet, A., Ekouevi, D.K., Touré, B., Patrick, A., Effi, B., et al. (2012) Cancer Screening by Visual Inspection in Cote d'Ivoire, Operational and Clinical Aspects According to HIV Status. BMC Public Health, 12, 237. http://dx.doi.org/10.1186/1471-2458-12-237

[15] Asonganyi, E., Vaghasia, M., Rodrigues, C., Phadtare, A., Ford, A., et al. (2013) Factors Affecting Compliance with Clinical Practice Guidelines for Pap Smear Screening among Healthcare Providers in Africa: Systematic Review and Meta-Summary of 2045 Individuals. PLoS ONE, 8, e72712. http://dx.doi.org/10.1371/journal.pone.0072712

[16] Zahedi, L., Sizemore, E., Malcolm, S., Grossniklaus, E. and Nwosu, O. (2014) Knowledge, Attitudes and Practices Regarding Cervical Cancer and Screening among Haitian Health Care Workers. International Journal of Environmental Research and Public Health, 11, 11541-11552. http://dx.doi.org/10.3390/ijerph111111541 